\title{
KARAKTERISTIK DAN POLA PENGOBATAN PASIEN PENDERITA HIPERTENSI DI PUSKESMAS WONOREJO TAHUN 2015
}

\author{
Jovi Sovia Mega, Victoria Yulita Fitriani, Arsyik Ibrahim \\ Puskesmas Wonorejo, Fakultas Farmasi Universitas Mulamarwan, Samarinda, \\ Kalimantan Timur \\ Email: Jovi_sovia@yahoo.co.id
}

\begin{abstract}
Abstrak
Hipertensi adalah kenaikan tekanan darah dalam arteri yang melebihi batas normal dan kenaikan ini bertahan pada keadaan istirahat dengan batas normal teratas tekanan sistolik $140 \mathrm{mmHg}$ dan tekanan diastolik $90 \mathrm{mmHg}$. Di Indonesia, tingkat kesadaran akan kesehatan masih rendah sehingga jumlah pasien yang tidak menyadari bahwa dirinya menderita hipertensi dan yang tidak mematuhi minum obat kemungkinan lebih besar. Penelitian ini bertujuan untuk mengetahui karakteristik pasien hipertensi dan mengetahui pola pengobatan pasien hipertensi. Metode penelitian ini dilakukan secara prospektif dan menggunakan kuesioner. Hasil penelitian Karakteristik pasien hipertensi di Puskesmas Wonorejo menunjukkan mayoritas pasien berjenis kelamin laki-laki (57\%), mayoritas pasien berumur 60-69 tahun (43\%), memiliki penyakit penyerta (47.2\%), lama menderita hipertensi selama 1-5 tahun $(33,33 \%)$, tidak ada riwayat hipertensi keluarga $(53,33 \%)$, berdasarkan gaya hidup, pasien yang kurang melakukan akivitas fisik $(53,33 \%)$, pasien yang biasa mengkonsumsi makanan asin $(66,66 \%)$, pasien yang biasa merokok $(26,67 \%)$ dan $(0 \%)$ tidak ada yang mengkonsumsi alkohol. Pola pengobatan pemilihan golongan dan jenis obat yang sering digunakan adalah golongan diuretik, ACE inhibitor, penghambat kanal kalsium dan agonis $\alpha_{2}$ sentral. Jenis obat yang digunakan yaitu Furosemid (10\%), Captopril (26,66 \%), Amlodipin (56,66\%), Nifedipin (6,66\%), Reserpine (6,66\%) dan Clonidine $(3,33 \%)$.
\end{abstract}

Kata Kunci: Hipertensi, Karakteristik, Pola Pengobatan

\begin{abstract}
Hypertension is a rise in blood pressure in the arteries that exceed normal limits and these increases persist on rest with systolic pressure of $140 \mathrm{mmHg}$ and diastolic pressure of 90 $\mathrm{mmHg}$. In Indonesia, the level of health awareness is still low so that the number of patients who did not realize that they suffering hypertension and obey to take medication are higher. The aims of this research are to determine the characteristics of patient and to know the hypertensive's treatment. The method of research is prospective and using questionnaire. The result of characteristic hypertension patiens at Wonorejo public health centert are almost patient are male (57\%), with aged is 60-69 years (43\%), have another disease (47.2\%), have hypertension for 1-5 year (33.33\%), there is no family history of hypertension (53.33\%), based on lifestyle, patients who less physical activity (53.33\%), patients who consume salty foods (66.66\%), patients who smoker is $(26.67 \%)$ and $(0 \%)$ for alcohol consume. Selecting treatment patterns classes and types of drugs commonly used was diuretics, ACE inhibitor, calcium channal blockers and central $\alpha 2$ agonists. The type
\end{abstract}


of drug used Furosemide (10\%), Captopril (26.66\%), amlodipine (56.66\%), Nifedipine $(6.66 \%)$, reserpine $(6.66 \%)$ and Clonidine $(3.33 \%)$.

Keywords: Hypertension, Characteristics, Treatment Pattern

\section{PENDAHULUAN}

Hipertensi dikenal secara luas sebagai penyakit kardiovaskular. Diperkirakan telah menyebabkan $4.5 \%$ dari beban penyakit secara global, dan prevalensinya hampir sama besar di negara berkembang maupun di negara maju. Hipertensi merupakan salah satu faktor risiko utama gangguan jantung. Selain mengakibatkan gagal jantung, hipertensi dapat berakibat terjadinya gagal ginjal maupun penyakit serebrovaskular. Penyakit ini bertanggung jawab terhadap tingginya biaya pengobatan dikarenakan alasan tingginya angka kunjungan ke dokter, perawatan di rumah sakit atau penggunaan obat jangka panjang (Anonim, 2006).

Pada kebanyakan kasus, hipertensi terdeteksi saat pemeriksaan fisik karena alasan penyakit tertentu, sehingga sering disebut sebagai "silent killer". Tanpa disadari penderita mengalami komplikasi pada organ-organ vital seperti jantung, otak ataupun ginjal (Setyani, 2006).

Hipertensi adalah kenaikan tekanan darah dalam arteri yang melebihi batas normal dan kenaikan ini bertahan, dimana pada keadaan istirahat batas normal teratas untuk tekanan sistolik $140 \mathrm{mmHg}$ sedangkan tekanan diastolik $90 \mathrm{mmHg}$ (Komaling, 2013).

Menurut data Lancet menyebutkan, jumlah penderita hipertensi di India tahun 2000 adalah 60,4 juta dan diperkirakan sebanyak 107,3 juta pada tahun 2025 (terjadi kenaikan sebesar 56\%). Dua pertiga penderita hipertensi hidup di negara miskin dan berkembang. Berdasarkan data WHO dari $50 \%$ penderita hipertensi yang diketahui hanya $25 \%$ yang mendapat pengobatan, dan hanya $12,5 \%$ yang diobati dengan baik. Tiap tahunnya 7 juta orang diseluruh dunia meninggal akibat hipertensi. Tahun 2000 saja hampir 1 miliar penduduk dunia menderita hipertensi. Menurut laporan WHO bulan September 2011, disebutkan bahwa hipertensi menyebabkan 8 juta kematian per tahun diseluruh dunia dan 1,5 juta kematian per tahun di wilayah Asia Tenggara (Komaling, 2013).

Menurut Riset Kesehatan Dasar, jumlah penderita hipertensi di Indonesia tahun 2007 adalah 31,7\% dan terjadi penurunan pada tahun 2013 yaitu 25,8\%. Di Amerika, menurut National Health and Nutrition Examination Survey (NHNES III), paling sedikit 30\% pasien hipertensi tidak menyadari kondisi mereka, dan hanya $31 \%$ pasien yang diobati mencapai target tekanan darah yang diinginkan dibawah 140/90 mmHg. Di Indonesia, dengan tingkat kesadaran akan kesehatan yang lebih rendah, jumlah pasien yang tidak menyadari bahwa dirinya menderita hipertensi dan yang tidak mematuhi minum obat kemungkinan lebih besar (Anonim, 2006).

\section{METODE PENELITIAN}

Penelitian ini dilakukan secara deskriptif dengan pengambilan data cara prospektif. Metode yang digunakan adalah teknik Sampling Accindental. Jumlah keseluruhan sampel 30 pasien dengan kriteria inklusi, yaitu adalah semua pasien penderita hipertensi, bersedia menjadi responden penelitian dan bertempat tinggal di wilayah tempat objek penelitian.

Pengambilan data pada penelitian ini menggunakan kuesioner. Berdasarkan kuesioner tersebut didapatkan informasi berupa mengenai pasien seperti jenis kelamin, umur, faktor resiko, penyakit penyerta dan obat yang digunakan. 


\section{HASIL DAN PEMBAHASAN}

\section{Karakteristik Pasien}

\section{Gambaran Penderita Berdasarkan Jenis Kelamin}

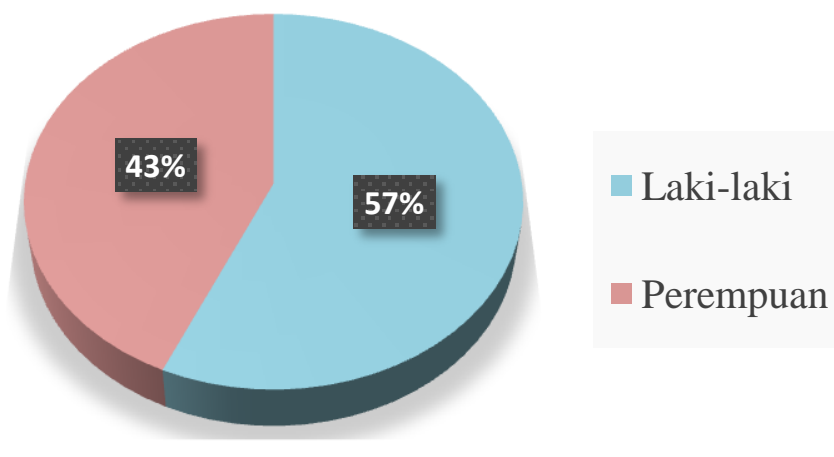

Gambar 1. Diagram Distribusi Hipertensi Berdasarkan Jenis Kelamin

Hasil yang diperoleh dari 30 pasien penderita hipertensi dipuskesmas wonorejo yaitu banyak terjadi pada laki-laki sekitar $57 \%$ sedangkan pada perempuan $43 \%$. Pada penelitian ini dapat terlihat bahwa laki-laki lebih banyak dibandingkan perempuan.

Prevalensi penderita hipertensi lebih sering ditemukan pada laki-laki dari pada perempuan, hal ini disebabkan pada umumnya yang bekerja adalah laki-laki, dan pada saat mengatasi masalah laki-laki cenderung untuk emosi dan mencari jalan pintas seperti merokok, minum-minuman alkohol, dan pola makan yang tidak baik sehingga tekanan darahnya dapat meningkat. Sedangkan perempuan dalam mengatasi masalah dan stres, masih dapat mengatasinya dengan tenang dan lebih stabil. Tetapi tekanan darah cenderung meningkat pada wanita setelah menopause daripada sebelum menopause, hal ini disebabkan oleh faktor dan adanya perubahan dalam diri perempuan tersebut (Sianturi, 2005).

Hasil yang diperoleh sesuai dengan teori, ini bisa disebabkan karena prilaku kurang sehat pada pria, berdasarkan hasil yang diperoleh dari gaya hidup seperti merokok dan suka mengkonsumsi makanan asin lebih banyak dialami pada laki-laki, sehingga laki-laki lebih banyak mengalami hipertensi dipuskesmas wonorejo.

\section{Gambaran Penderita Berdasarkan Usia}

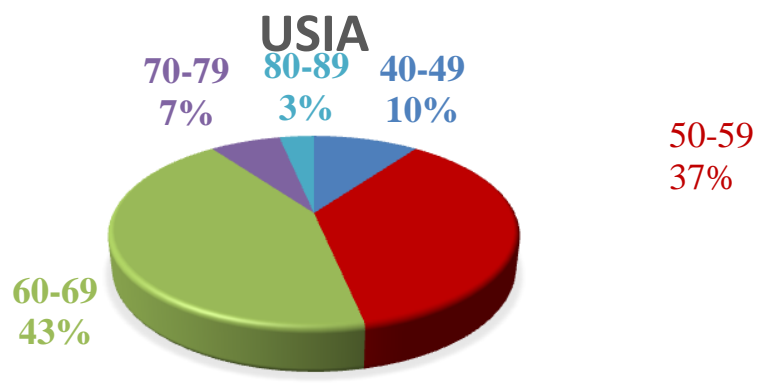

Gambar 2. Diagram Distribusi Hipertensi Berdasarkan usia 
Hasil yang diperoleh, data menunjukan distribusi responden yang berumur 40-49 tahun sebanyak 10\%, pada umur 50-59 tahun sebanyak 37\%, pada umur 60-69 tahun sebanyak 43\%, pada umur 70-79 tahun sebanyak 7\%, dan pada umur 80-89 tahun sebanyak 3\%. Setelah umur 45 tahun tekanan darah akan semakin meningkat karena dinding arteri akan mengalami penebalan karena adanya penumpukan zat kolagen pada lapisan otot, sehingga pembuluh darah akan berangsur-angsur menyempit dan menjadi kaku (Lailatul, 2014). Dinding pembuluh darah yang mengeras atau kaku membutuhkan tekanan darah sistolik yang lebih tinggi agar darah dapat melewati pembuluh darah yang mengeras dibandingkan dengan pembuluh darah yang elastis (Wisudawan, 2012).

\section{Presentase jumlah pasien berdasarkan penyakit penyerta dan komplikasi}

Tabel 1. Distribusi pasien hipertensi berdasarkan penyakit penyerta dan komplikasi

\begin{tabular}{ccc}
\hline Diagnosa & Jumlah pasien & Presentase (\%) \\
\hline Hipertensi tanpa penyakit lain & 11 & 36.67 \\
Hipertensi dengan penyakit & 17 & 47.2 \\
penyerta & 2 & 6,6 \\
Hipertensi dengan DM & 30 & 100 \\
Total & & \\
\hline
\end{tabular}

Hasil yang diperoleh hipertensi tanpa penyakit lain sebesar $36.67 \%$ pasien menderita hipertensi murni, tanpa disertai adanya penyakit lain. Hipertensi dengan DM sebesar 6,6\%. Hipertensi merupakan penyakit yang sangat berpotensi untuk menimbulkan komplikasi, dan DM merupakan komplikasi yang umum terjadi.

Hipertensi merupakan faktor resiko utama untuk terjadinya DM. Hubungannya dengan DM tipe 2 sangatlah kompleks, hipertensi dapat membuat sel tidak sensitif terhadap insulin (resisten insulin). Padahal insulin berperan meningkatkan ambilan glukosa dibanyak sel dan dengan cara ini juga mengatur metabolisme karbohidrat, sehingga jika terjadi resistensi insulin oleh sel, maka kadar gula didalam darah juga dapat mengalami gangguan. Kadar insulin berlebih menimbulkan peningkatan retensi natrium oleh tubulus ginjal yang dapat menyebabkan hipertensi (Mutmainil, 2013).

Hipertensi dengan penyakit penyerta sebesar $47.2 \%$ yaitu asam urat, asma, maag, alergi dan batu empedu. Penyakit penyerta yang menyebabkan diresepkan obat-obat lain selain obat antihipertensi.

\section{Presentase jumlah pasien berdasarkan lama menderita hipertensi}

Tabel 2. Distribusi pasien hipertensi berdasarkan lama menderita hipertensi

\begin{tabular}{ccc}
\hline $\begin{array}{c}\text { Lama menderita hipertensi } \\
\text { (tahun) }\end{array}$ & Jumlah pasien & Presentase (\%) \\
\hline$<1$ & 8 & 26,67 \\
$1-5$ & 10 & 33,33 \\
$5-10$ & 6 & 20 \\
$>10$ & 6 & 20 \\
Total & 30 & 100 \\
\hline
\end{tabular}


Data yang diperoleh berdasarkan lama menderita hipertensi, menunjukkan bahwa pasien yang memiliki hipertensi selama $<1$ tahun yaitu $26,67 \%$, pada pasien yang memiliki hipertensi selama 1-5 tahun yaitu 33,33\%, pada pasien yang memiliki hipertensi selama 510 tahun dan $>10$ yaitu 20\%. Mayoritas pasien penderita hipertensi yang telah menderita penyakit tersebut selama 1-5 tahun yaitu 33,33\%. Lama menderita hipertensi merupakan lama seseorang menderita hipertensi terhitung sejak pertama kali mengalami tekanan darah diatas normal.

\section{Gambaran Penderita Berdasarkan Riwayat Keluarga}

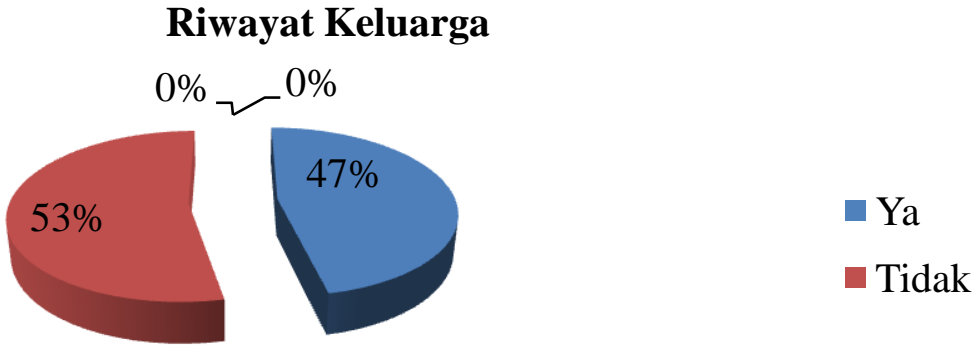

Gambar 5.3. Diagram Distribusi Hipertensi Berdasarkan Riwayat Keluarga

Hasil penelitian yang diperoleh dari riwayat hipertensi keluarga yaiu $46.67 \%$ dan yang tidak ada riwayat hipertensi keluarga yaitu 53,33\% yang menunjukkan bahwa lebih banyak yang tidak ada riwayat dari keluarga dengan kejadian hipertensi . Riwayat keluarga yang menunjukkan adanya tekanan darah yang tinggi merupakan faktor resiko paling kuat bagi seseorang untuk mengidap hipertensi dimasa yang akan datang. Penyebab hipertensi karena faktor riwayat keluarga ini diketahui disebabkan oleh pola hidup yang kurang baik. Dikaitkan dengan pola makan, jika seseorang menerapkan pola makan yang baik, kemungkinan orang tersebut akan terhindar dari hipertensi (Yufita, 2010).

\section{Presentase jumlah pasien hipertensi berdasarkan gaya hidup}

Tabel 3. Distribusi pasien hipertensi berdasarkan gaya hidup

\begin{tabular}{cccc}
\hline Gaya hidup & Jenis kelamin & Ya & Tidak \\
\hline \multirow{2}{*}{$\begin{array}{c}\text { Melakukan aktivitas } \\
\text { fisik }\end{array}$} & Laki-laki & $10(33,33 \%)$ & $7(23,33 \%)$ \\
\cline { 2 - 4 } & Perempuan & $4(13,33 \%)$ & $9(30 \%)$ \\
\hline Suka makanan asin & Laki-laki & $13(43,33 \%)$ & $4(13,33 \%)$ \\
\cline { 2 - 4 } & Perempuan & $7(23,33 \%)$ & $6(20 \%)$ \\
\hline Kebiasaan merokok & Laki-laki & $8(26,67 \%)$ & $9(30 \%)$ \\
\cline { 2 - 4 } & Perempuan & 0 & $13(43,33 \%)$ \\
\hline \multirow{2}{*}{$\begin{array}{c}\text { Kebiasaan konsumsi } \\
\text { alkohol }\end{array}$} & Laki-laki & 0 & $17(56,67 \%)$ \\
\cline { 2 - 4 } & Perempuan & 0 & $13(43,33 \%)$ \\
\hline
\end{tabular}


Hasil penelitian yang diperoleh berdasarkan akivitas fisik, sebanyak 53,33\% pasien hipertensi kurang melakukan akivitas fisik. Kurangnya akifitas fisik meningkatkan risiko menderita hipertensi karena meningkakan risiko kelebihan berat badan. Orang yang tidak akif juga cenderung mempunyai frekuensi denyut jantung yang lebih tinggi sehingga otot jantungnya harus bekerja lebih keras pada setiap kontraksi. Makin keras dan sering otot jantung harus memompa, makin besar tekanan yang dibebankan pada arteri. Tekanan darah dipengaruhi oleh akifitas fisik. Tekanan darah akan lebih tinggi pada saat melakukan akifitas fisik dan lebih rendah ketika beristirahat. Akifitas fisik adalah gerakan yang dilakukan oleh otot tubuh dan sistem penunjangnya. Selama melakukan akifitas fisik, otot membutuhkan energi diluar metabolisme untuk bergerak, sedangkan jantung dan paru-paru memerlukan tambahan energi untuk mengantarkan zat-zat gizi dan oksigen keseluruh tubuh dan untuk mengeluarkan sisa-sisa dari tubuh (Mannan, 2012).

Hasil yang diperoleh dari kebiasaan dalam mengkonsumsi makanan asin atau garam terhadap kejadian hipertensi, sebanyak $66,66 \%$ pasien hipertensi yang mempunyai kebiasaan dalam mengkonsumsi makanan asin atau garam. Pengaruh asupan terhadap hipertensi terjadi melalui peningkatan volume plasma, curah jantung dan tekanan darah. Garam menyebabkan penumpukan cairan dalam tubuh, karena menarik cairan diluar sel agar tidak keluar, sehingga akan meningkatkan volume dan tekanan darah (Sheps, 2005).

Hasil yang diperoleh berdasarkan dari kebiasaan merokok, sebanyak 26,67\% pasien hipertensi yang mempunyai kebiasaan merokok. Hipertensi dirangsang oleh adanya nikotin dalam batang rokok yang dihisap seseorang. Hasil peneliti menunjukkan bahwa nikotin dapat meningkatkan penggumpalan darah dalam pembuluh darah. selain itu, nikotin juga dapat menyebabkan terjadinya penggapuran pada dinding pembuluh darah (Puspita, 2014).

Kebiasaan pada pasien hipetensi dalam mengkonsumsi alkohol. Hasil yang diperoleh baik dari laki-laki maupun perempuan tidak ada yang mengkonsumsi alkohol. Namun hipertensi merupakan jenis penyakit yang memiliki banyak faktor risiko, sehingga tidak menutup kemungkinan bahwa mereka yang tidak mengkonsumsi alkohol juga bisa terkena penyakit ini. Akan tetapi apabila seseorang mengkonsumsi alkohol, maka risiko untuk mengalami hipertensi juga meningkat. Hampir 5-20\% kasus hipertensi diperkirakan terjadi akibat konsumsi alkohol yang berlebihan (Lailatul, 2014).

\section{Pola Pengobatan Pasien Hipertensi}

Tabel 4. Distribusi pasien Penderita Hipertensi berdasarkan pola pengobatan

\begin{tabular}{ccc}
\hline Golongan obat & Jenis obat & Presentase (\%) \\
\hline Diuretik & Furosemid & $3(10 \%)$ \\
\hline ACEI & Captopril & $8(26,66 \%)$ \\
\hline CCB & Amlodipin & $17(56,66 \%)$ \\
\cline { 2 - 3 } & Nifedipin & $2(6,66 \%)$ \\
\hline Agonis $\alpha_{2}$ sentral & Reserpine & $2(6,66 \%)$ \\
\cline { 2 - 3 } & Clonidine & $1 \quad(3,33 \%)$ \\
\hline
\end{tabular}

Hasil yang diperoleh ada 4 golongan antihipertensi yang digunakan dalam terapi hipertensi di Puskesmas Wonorejo. Golongan ACEI obat yang digunakan yaitu captopril yang diberikan tunggal sebanyak 26,66\%. Pasien yang mendapat obat antihipertensi yang diberikan tunggal sebanyak $26,66 \%$ sudah sesuai dengan standar pola pengobatan menurut 
JNC7 untuk hipertensi stage 1 (TDS 140-159 atau TDD 90-99 mmHg) diberikan salah satu golongan nya yaitu ACEI.

ACEI dianggap sebagai lini kedua setelah diuretik pada kebanyakan pasien dengan hipertensi. Pada studi dengan lansia, ACEI sama efektifnya dengan dengan diuretik dan penyekat beta, kebanyakan klinis setuju bila ACEI bukan merupakan terapi lini pertama pada kebanyakan pasien hipertensi. ACEI menghambat perubahan angiotensin I menjadi angiotensin II, dimana angiotensin II adalah vasokontriktor poten yang juga merangsang sekresi aldosteron. ACEI juga memblok degradasi bradikinin dan merangsang sistem zatzat yang menyebabkan vasodilatasi, termasuk prostaglandin dan protasiklin. Peningkatan bradikinin meningkatkan efek penurunan tekanan darah dari ACEI. Tetapi juga bertanggung jawab terhadap efek samping batuk kering yang sering dijumpai pada penggunaan ACEI (Anonim, 2006).

Golongan CCB obat yang digunakan yaitu amlodipin sebanyak 56,66\% dan nifedipin sebanyak $6,66 \%$ yang diberikan tunggal. Pasien yang mendapat obat antihipertensi sesuai dengan standar pola pengobatan menurut JNC7 untuk hipertensi tahap 1 (TDS 140-159 atau TDD 90-99 $\mathrm{mmHg}$ ) diberikan salah satu golongannya yaitu penghambat kanal kalsium.

Penghambat kanal kalsium bukan golongan lini pertama tetapi golongan antihipertensi sangat efektif. Beberapa Data menunjukkan bahwa dihidropiridin tidak memberikan banyak perlindungan terhadap penyakit jantung jika dibandingkan dengan terapi diuretik dan $\beta$-blocker atau ACE inhibitor pada hipertensi tanpa komplikasi. Pada pasien dengan hipertensi dan diabetes, ACE inhibitor tampaknya lebih kardioprotektif dari dihidropiridin (Dipiro, 2005).

Golongan Agonis $\alpha_{2}$ sentral obat yang digunakan yaitu reserpine sebanyak $(6,66 \%)$ dan klonidine sebanyak $(3,33 \%)$ diberikan secara tunggal. Pasien yang mendapat obat antihipertensi kurang sesuai dengan standar pola pengobatan menurut JNC7 untuk hipertensi tahap 1 (TDS 140-159 atau TDD 90-99 $\mathrm{mmHg}$ ) diberikan salah satu golongannya yaitu Agonis $\alpha_{2}$ sentral. Kurang sesuai untuk obat reserpine karena pada pemberiannya harus dikombinasikan. Reserpin dapat menyebabkan retensi natrium dan air yang cukup bermakna. sehingga, harus dikombinasikan dengan diuretik.

Klonidin merupakan Agonis $\alpha_{2}$ sentral menurunkan tekanan darah terutama dengan merangsang reseptor $\alpha_{2}$ adrenergik diotak. Perangsangan ini menurunkan aliran simpatetik dari pusat vasomotor diotak dan meningkatkan tonus vagal. Penurunan aktivitas simpatetik, bersamaan dengan meningkatnya aktivitas parasimpatetik, dapat menurunkan denyut jantung, cardiac output, total pheripheral resisten, aktivitas plasma renin dan reflex baroreseptor. Klonidin sering digunakan untuk hipertensi yang resistan. Penggunaan klonidin dosis kecil dapat digunakan untuk mengobati hipertensi tanpa penambahan diuretik (Anonim, 2006).

Reserpin merupakan Agonis $\alpha_{2}$ sentral menurunkan tekanan darah dengan mengosongkan norepinefrin dari ujung saraf simpatetik dan memblok perjalanan norepinefrin ke granul penyimpanannya. Reserpin juga mengosongkan katekolamin dari otak dan miokardium, mengakibatkan sedasi, depresi, dan berkurangnya curah jantung. Reserpin mulai bekerja dan waktu paruhnya lambat sehingga dosis pemberian satu kali perhari. Tetapi, diperlukan 2 sampai 6 minggu sebelum efek antihipertensi maksimal terlihat. Reserpin dapat menyebabkan retensi natrium dan air yang cukup bermakna. Harus dikombinasikan dengan diuretik. Penghambatan aktivitas simpatetik yang kuat oleh reserpin mengakibatkan meningkatnya aktivitas parasimpatetik. Reserpin digunakan sebagai terapi lini ketiga pengobatan hipertensi (Anonim, 2006).

Hasil penggunaan obat yang dikombinasikan dipuskesmas yaitu kombinasi antara amlodipin dengan furosemid dan captopril yang dikombinasikan dengan furosemid sudah 
sesuai dengan standar pola pengobatan hipertensi menurut JNC7, karena untuk keadaan klinis pasien dengan tekanan darah yang termasuk dalam tahap 2 (TDD $\geq 160$ atau $\geq 100$ $\mathrm{mmHg}$ ) pada umumnya diberikan dengan kombinasi 2 obat.

Diuretik merupakan lini pertama sebagian besar pasien dengan hipertensi. Selain itu, ketika terapi kombinasi yang dibutuhkan dalam hipertensi untuk mengendalikan tekanan darah, diuretik direkomendasikan sebagai salah satu yang digunakan. Tiazid adalah tipe diuretik yan disukai untuk mengobati hipertensi. Tiazid adalah diuretik yang paling efektif untuk menurunkan tekanan darah, untuk fungsi ginjal menurun, diuretik yang diperlukan untuk melawan peningkatan terkait dalam retensi natrium dan air yaitu loop diuretik (misalnya furosemid dosis dua kali sehari) harus dipertimbangkan. Diuretik idealnya diberikan pada pagi hari jika diberikan sekali sehari dan di pagi hari dan sore hari jika dosis dua kali sehari untuk meminimalkan risiko diuresis nokturnal (Dipiro, 2005).

Pengobatan Diabetes Mellitus yang digunakan yaitu golongan sulfonilurea. Golongan ini mempunyai efek utama meningkatkan sekresi insulin oleh sel beta pankreas, sehingga menjadi pilihan utama untuk pasien dengan berat badan normal dan kurang dan masih boleh diberikan pada pasien dengan berat badan lebih. Obat yang digunakan adalah glibenklamid. Untuk Diabetes Mellitus obat hipertensi yang dikombinasi yaitu amlodipin dan glibenklamid. Amlodipin merupakan golongan CCB yang merupakan Drug Of Choice untuk penanganan hipertensi dengan diabetes mellitus (Nurul, 2008).

Golongan penghambat kanal kalsium diberikan untuk kontrol tekanan darah pada pasien hipertensi dengan diabetes. Data tidak menunjukkan bahwa CCB berbahaya pada pasien diabetes tetapi menunjukkan bahwa mereka tidak protektif seperti ACE inhibitor. ACE inhibitor atau ARB sebagai lini pertama yang lebih disukai untuk mengendalikan hipertensi pada diabetes (Dipiro,2005).

Tabel 5. Kesesuaian penggunaan obat antihipertensi di Puskesmas Wonorejo Menurut JNC7

\begin{tabular}{cccc}
\hline No. & Golongan Obat & $\begin{array}{c}\text { Kesesuaian } \\
\text { Presentase } \\
\text { Pasien }\end{array}$ & $\begin{array}{c}\text { Penggunaan Obat } \\
\text { Menurut JNC7 }\end{array}$ \\
\hline 1 & Diuretik & $10 \%$ & $100 \%$ \\
2 & ACEI & $26,66 \%$ & $100 \%$ \\
3 & CCB & $63,32 \%$ & $100 \%$ \\
4 & Agonis $\alpha_{2}$ sentral & $9,99 \%$ & $50 \%$ \\
\hline
\end{tabular}

Hasil yang diperoleh berdasarkan dari golongan obat yang sesuai penggunaan obat menurut JNC7 untuk hipertensi yang tahap 1 (TDS 140-159 atau 90-99 $\mathrm{mmHg}$ ) sudah sesuai dengan standar pola pengobatan karena untuk pasien hipertensi yang tanpa komplikasi umumnya diberikan golongan ACE inhibitor, penghambat kanal kalsium atau agonis $\alpha_{2}$ sentral. Untuk golongan ACE inhibitor dan penghambat kanal kalsium untuk hipertensi tahap 1 diberikan tunggal pada pasien, beda dengan golongan agonis $\alpha_{2}$ sentral ada sebagian obat dari golongan ini harus diberikan dalam kombinasi dengan diuretik. Salah satu obat golongan agonis $\alpha_{2}$ sentral yang harus dikombinasi dengan diuretik yaitu Reserpine. Karena obat reserpine bisa menyebabkan retensi natrium dan air. Harus dikombinasikan dengan diuretik (Dipiro, 2005). Sedangkan data yang diperoleh reserpine diberikan tunggal tidak dikombinasikan dengan golongan diuretik. 
Pengobatan hipertensi tahap 2 (TDS $\geq 160$ atau TDD $\geq 100 \mathrm{mmHg}$ ) juga sudah sesuai dengan standar pola pengobatan menurut JNC7. Pasien hipertensi yang tanpa komplikasi umumnya diberikan kombinasi 2 obat. Data yang diperoleh yaitu golongan diuretik dengan golongan ACE inhibitor dan diuretik dengan golongan penghambat kanal kalsium. Menurut JNC7 untuk pasien dengan komplikasi juga sudah sesuai yaitu salah satunya penggunaan pada golongan penghambat kanal kalsium. Golongan penghambat kanal kalsium merupakan Drug Of Choice untuk penanganan hipertensi dengan diabetes mellitus (Nurul, 2008).

\section{KESIMPULAN}

Berdasarkan hasil penelitian karakteristik dan pola pengobatan pada pasien penderita hipertensi di Puskesmas Wonorejo, maka dapat disimpulkan sebagai berikut :

a. Karakteristik pasien hipertensi berdasarkan jenis kelamin yang paling banyak yaitu laki-laki sebanyak 17 (56,67\%). Berdasarkan umur yang paling banyak yaitu umur 6069 tahun sebanyak 43\%, Berdasarkan penyakit penyerta yang paling banyak yaitu sekitar 17 orang $(47.2 \%)$. Berdasarkan lama menderita hipertensi yang paling banyak yaitu selama 1-5 tahun (33,33\%). Berdasarkan adanya riwayat hipertensi keluarga yang paling banyak yaitu tidak ada riwayat hipertensi keluarga 16 pasien $(53,33 \%)$. Berdasarkan gaya hidup, dari akivitas fisik, sebanyak 53,33 \% pasien hipertensi kurang melakukan akivitas fisik, dari kebiasaan dalam mengkonsumsi makanan asin sebanyak 66,66\%, dari kebiasaan merokok, sebanyak 26,67\%, dari kebiasaan dalam mengkonsumsi alcohol tidak ada yang mengkonsumsi alkohol (0\%).

b. Pola pengobatan berdasarkan pemilihan golongan dan jenis obat yang paling sering digunakan adalah golongan diuretik, ACE inhibitir, penghambat kanal kalsium dan agonis $\alpha_{2}$ sentral. Jenis obat yang sering digunakan yaitu Furosemid (10\%), Captopril $(26,66 \%)$, Amlodipin (56,66 \%), Nifedipin (6,66\%), Reserpine (6,66\%) dan Clonidine $(3,33 \%)$.

\section{Saran}

Perlunya dilakukan pemberian informasi mengenai hipertensi dan dampak yang terjadi ketika pasien tidak berobat dan tidak meminum obatnya pada saat pasien pergi berobat di Puskesmas Wonorejo.

\section{DAFTAR PUSTAKA}

1. Anonim. 2006. Pharmaceutical Care Untuk Penyakit Hipertensi. Direktorat Bina Farmasi Komunitas dan Klinik Ditjen Bina Kefarmasian dan Alat Kesehatan Departemen Kesehatan. Jakarta.

2. Komaling Jeine Kristy, dkk. 2013. Hubungan mengonsumsi alkohol dengan Kejadian Hipertensi pada Laki-Laki di Desa Tompasobaru II Kecamatan Tompasobaru Kabupaten Minahasa Selatan. Ejurnal keperawatan.

3. Setyani wahyuning, dkk. 2006. Evaluasi Drug Related Problem (DRP s $_{\text {s }}$ pada Pasien Hipertensi Rawat Jalan Di Instalasi Farmasi Rumah Sakit Umum Pemerintah Kota Semarang. Jurnal Media Farmasi Indonesia. Yogyakarta.

4. Sianturi Efendi, 2005. Strategi Pencegahan Hipertensi Esensial Melalui Pendekatan Faktor Resiko Di Rumah Sakit Umum Dr. Dirngadi Kota Medan. USU e-Respository

5. Lailatul Najmi Raihan, Erwin, Ari Dristiana Dewi. 2014. Faktor-Faktor Yang Berhubungan Dengan Kejadian Hipertensi Primer Pada Masyarakat Di Wilayah Kerja Puskesmas Rumbai Pesisir. Jurnal JOM PSIK. 1, (2).

6. Nurul Mutmainah, Syafiah Ernawati dan EM Sutrisna. 2008. Identifikasi Drug Related Problems (DRPs) Potensial Kategori Ketidakpatuhan Pemilihan Obat. Pada Pasien 
Hipertensi Dengan Diabetes Mellitus Di Instalasi Rawat Inap Rumah Sakit X Jepara Tahun 2007. Jurnal Pharmacon, 9. (1).

7. Puspita Eva, Yasir Haskas. 2014. Faktor Risiko Kejadian Hipertensi Pada Pasien yang Berobat Dipoliklinik Rumah Sakit Umum Daerah Labuang Baji Makassar. Jurnal Ilmiah Kesehatan Diagnosis. 5. (1).

8. Dipiro J.T dkk. 2005. Pharmacotherapy: A Pathophysiologic Approach Sixth Edition. MC GRAW-HILL Medical Publishing Division. Unites State of America.

9. Sheps, Shel Don G, Maya Clinic Hipertensi. 2005. Mengatasi Tekanan Darah Tinggi. PT Intisari Mediatama. Jakarta.

10. Mutmainil Iin, 2013. Hubungan Kadar Gula Darah Dengan Hipertensi Pada Pasien DM Tipe 2 Dirumah Sakit Umum Daerah Karanganyar. Naskah Publikasi.

11. Wisudawan, Agus, Prabojo Pribadi dan Puspita Septi. 2012. Gambaran Penggunaan Antihipertensi di Poliklinik Penyakit Dalam RSUD Tidar Kota Magelang Periode Januari-Juni 2012. Jurnal Fakultas Ilmu Kesehatan UMM. 3. (2).1-11.

12. Yufita Yeni, Siti Nur Djannah, Solikhah. 2010. Faktor-Faktor Yang Berhubungan Dengan Kejadian Hipertensi Pada Wanita Usia Subur Di Puskesmas Umbulhaijo I Yogyakarta Tahun 2009. Yogyakarta.

13. Mannan Hasrin, Wahiduddin, Rismayanti. 2012. Faktor Risiko Kejadian Hipertensi Diwilayah Kerja Puskesmas Bangkala Kabupaten Jeneponto Tahun 2012. 